\title{
Neonatal Bacterial Infections in Parakou in 2013
}

\author{
Joseph Agossou 1*, Marcelline Hounnou-d'Almeida², Alphonse Noudamadjo1, \\ Julien Didier Adédémy1', Wèrè Sylvestre Nékoua1, Blaise Ayivi² \\ ${ }^{1}$ Mother \& Child Department, Faculty of Medicine, University of Parakou, and Borgou Regional University \\ Teaching Hospital in Parakou, Parakou, Benin \\ ${ }^{2}$ Mother \& Child Department, Faculty of Health Sciences (University of Abomey-Calavi) and National University \\ Teaching Hospital (CNHU-HKM), Cotonou, Benin \\ Email: "agossoujoseph@gmail.com
}

Received 6 February 2016; accepted 13 March 2016; published 16 March 2016

Copyright (C) 2016 by authors and Scientific Research Publishing Inc.

This work is licensed under the Creative Commons Attribution-NonCommercial International License (CC BY-NC). http://creativecommons.org/licenses/by-nc/4.0/

(c) (i) (8) Open Access

\begin{abstract}
Objective: Neonatal bacterial infections are a leading cause of mortality in developing countries, including Benin. This study aimed to investigate the epidemiological, clinical and bacteriological aspects of neonatal bacterial infections and their outcomes in the neonatal care unit of the Borgou Regional University Teaching Hospital (CHUD-Borgou). Study design: This manuscript described a cross-sectional study with prospective data collection and an analytical purpose that was performed over the course of $\mathbf{3}$ months. It was conducted in the neonatal care unit of CHUD-Borgou and focused on 203 newborns who were admitted for suspected bacterial infection. Results: Neonatal bacterial infections accounted for $63.75 \%$ of admissions. The sex ratio was $1: 1$. Prematurity was the main reason for admission (25.1\%), and respiratory distress was the most common physical symptom (22.2\%). From a bacteriological point of view, $14.7 \%$ of blood cultures were positive, and the main isolated pathogens were Escherichia coli $(35.8 \%)$, Staphylococcus aureus $(21.5 \%)$ and Klebsiella pneumoniae (14.3\%). These pathogens were more sensitive to aminoglycosides than to other antibiotics. Lethality was $21.6 \%$. Place of birth $\left(p<10^{-3}\right)$, age of the newborn at admission $(p=0.003)$ and maternal history of infectious diseases during pregnancy $(p=0.02)$ were factors associated with neonatal bacterial infections. Conclusion: This study identified the main pathogens responsible for neonatal bacterial infections and their level of sensitivity to antibiotics. It also determined the different factors associated with neonatal bacterial infections that should be considered in newborn care.
\end{abstract}

\section{Keywords}

Infectious Diseases, Neonatology, Parakou, Benin

\footnotetext{
${ }^{*}$ Corresponding author.
}

How to cite this paper: Agossou, J., Hounnou-d'Almeida, M., Noudamadjo, A., Adédémy, J.D., Nékoua, W.S. and Ayivi, B. (2016) Neonatal Bacterial Infections in Parakou in 2013. Open Journal of Pediatrics, 6, 100-108. 


\section{Introduction}

Neonatal infection is a global public health issue. According to WHO, globally, infection is the leading cause of mortality. In a joint report from WHO, UNICEF, USAID and UNFPA, neonatal bacterial infection is one of the top three causes of newborn death in Africa, ahead of prematurity and prenatal asphyxia [1]. In the West African sub-region, neonatal bacterial infection frequency in hospitals was $10.6 \%$ in the National University Teaching Hospital of Cotonou (South Benin) in 1991 [2], 65.2\% on the Ivory Coast in 2006 [3] and 58\% in Togo in 2010 [4]. Its etiological diagnosis faces enormous difficulties in countries with limited resources such as Benin. The consequence of this situation is an excessive diagnosis of neonatal infection and the over-prescription of antibiotics. According to international scientific literature, the main causative organisms are B. streptococcus, E. coli and Listeria monocytogenes. The aim of this research work was to investigate the epidemiological, clinical and etiological aspects of neonatal bacterial infections and their outcomes.

\section{Methods}

\section{- Study setting, type, period and population}

The study was conducted in the neonatal care unit of the pediatric ward and in the laboratory of the Borgou Regional University Teaching Hospital (CHUD-Borgou) located in Parakou (Republic of Benin). The neonatal care unit is rated at level $2 \mathrm{~b}$ and admits, on average, 1000 sick newborns per year.

It was a cross sectional study with prospective data collection and an analytical purpose that was performed over the course of 3 months from June 1 to August 31, 2013; it involved all the newborns who were hospitalized in the neonatal care unit during that time.

\section{- Inclusion criteria}

The study involved all newborns admitted for suspected bacterial infection if their parents gave their verbal informed consent.

The subjects considered as cases suspected of bacterial infection were newborns with at least an anamnestic criterion of infection or who showed at least one physical sign suggesting infection [5]-[7].

The anamnestic data were collected based on obstetrical records and also on interviews with the mothers of the children. The anamnestic criteria of bacterial infection that were adopted are the following [5]:

- urinary or genital infection, especially during the last three months of pregnancy,

- premature rupture of membranes (PROM),

- prolonged leakage of the amniotic fluid for $\geq 12$ hours,

- fetid, meconial amniotic fluid or staining,

- abnormalities of fetal heart rhythm or unexplained fetal asphyxia,

- repetition of obstetrical gestures in the delivery room, with a prolonged labor,

- maternal fever before, during or after delivery,

- spontaneous preterm birth at $<37$ weeks of amenorrhea (WA),

- a twin suffering from maternal-fetal infection.

The physical symptoms suggestive of bacterial infection were:

- general signs (fever or more often hypothermia or thermal instability, overall poor impression, gray skin complexion, pallor),

- cardiovascular symptoms (state of shock, pallor, cyanosis of the extremities, marbling, gray skin complexion, tachycardia, capillary refill time (CRT) $>3$ seconds, collapse),

- respiratory symptoms (respiratory distress, grunting respirations, crepitant rales),

- neurological symptoms (hypotonia or hypertonia, tremors or convulsions, bulging anterior fontanelle, somnolence or irritability, disturbance or absence of primitive reflexes),

- hepatic-gastric symptoms (refusal to breastfeed, abdominal bloating, dirty gastric residuals, gastric releases, vomiting, diarrhea, hepatosplenomegaly),

- mucocutaneous signs (suppuration of the umbilicus, pustules, jaundice, scleredema).

\section{- Sampling}

The selection of respondents was exhaustive and focused on all newborns suspected of bacterial infection.

\section{- Study variables}

Neonatal bacterial infection was the dependent variable. The independent variables were related to:

- the mothers of the newborns (their age, if infectious pathologies were present during pregnancy, the final pe- 
riod of pregnancy, the birth place of their newborn and route of delivery),

- the newborns (their age on admission, sex, reason for admission, physical examination data, blood culture results, results of cytobacteriological analysis of cerebrospinal fluid and gastric fluid samples, hemogram results, C-reactive protein results, outcome and output mode).

\section{- Procedure}

For each newborn involved in this study, the same diagnosis process was followed by the same medical examiner. All cases suspected of neonatal bacterial infection were identified based on anamnestic and physical symptoms.

Then, samples were collected in order to perform different biological tests and analyses at the CHUD-Borgou laboratory. Blood samples were used for a hemogram, determination of C-reactive protein and blood culture collected on admission. Gastric fluid samples were collected from newborns who were transferred immediately after their birth (within 6 hours) from the maternity department of CHUD-Borgou and were sent to the bacteriology laboratory for seeding, culture and antibiotic susceptibility testing. A lumbar puncture was performed on all newborns who were suspected of neonatal bacterial infection with cytobacteriological and biochemical testing of cerebrospinal fluid.

After sample collection, a probabilistic antibiotic treatment was put in place as the first choice according to a pre-existing protocol applicable in the unit, which consisted of betalactamin and aminoside treatment, (amoxicillin/ampicillin and gentamycin/netilmicin treatment). Then, the treatment was readjusted on the basis of clinical progression and the results of antibiotic susceptibility testing.

\section{- Definition of neonatal bacterial infection}

All newborns were considered infected if suspected of bacterial infection on admission or during clinical progression or if an obvious physical symptom of infection and/or one or several paraclinical signs suggestive of bacterial infection was observed. The paraclinical test used to support bacterial infection diagnosis consisted of:

- positive blood culture,

- positive CRP (with a serum level $\geq 6 \mathrm{mg} / \mathrm{l}$ ),

- hyperleukocytosis (white blood cell count $\geq 25 \mathrm{G} / 1$ ),

- leucopenia (white blood cell count $<5 \mathrm{G} / \mathrm{l}$ ),

- thrombocytopenia (platelet count $<150 \mathrm{G} / \mathrm{l}$ ),

- pleocytosis during cyto-bacteriological study of CSF $\left(\geq 20\right.$ leukocytes $\left./ \mathrm{mm}^{3}\right)$ predominated by neutrophils [8], with hypoglycorrhachia $<0.40 \mathrm{~g} / \mathrm{l}$ and hyperproteinorachia $>0.40 \mathrm{~g} / \mathrm{l}$.

- Data processing and analysis

The medical record data for mothers and their newborns were collected on individual sheets and then captured with Epi info software version 3.5.1., which analyzed the data using SPSS software version 16.0. Qualitative variables were described as percentages. The association degree of variables of exposure with dependent variables was determined by calculating the relative risk with a 95\% confidence interval. Proportions were compared by means of Pearson's chi-squared test for large numbers and Fischer's test for small numbers, and p-values lower than 0.05 were considered to be significant.

\section{- Limits and difficulties}

The lack of a funding source for this research work was the main limiting factor. The high cost of paraclinical tests was subsidized by, especially for performing hemograms, CRP, cytobacteriological and biochemical testing of cerebrospinal fluid; however, costs were not incurred by the parents. The same applied to blood cultures for which only one-half of the cost was incurred by the parents. Notwithstanding that motivating factor, several parents were unable to pay for the blood culture even when the cost had been reduced by half. This situation was the reason why a blood culture was not performed for all the newborns in the study. Moreover, gastric fluid collection was not been possible for all newborns.

\section{- Ethical considerations}

Collection of patient information was anonymous and confidential. The ethical committee of the Faculty of Medicine of Parakou authorized us to conduct this study, and the parents of the newborns involved in this study also gave their verbal consent.

\section{Results}

Among the 240 newborns who were hospitalized in the CHUD-Borgou neonatal care unit during the study period, 203 were suspected of neonatal bacterial infection and were therefore candidates for this study. Among the 
newborns involved in the study, 153 were infected based on clinical and paraclinical criteria, which resulted in a frequency of $63.8 \%$.

\section{- Sociodemographic characteristics}

Among the 203 mothers, 176 (86.7\%) were between 18 and 35 years of age, 11, (5.4\%) were under 18 years of age and 16 (7.9\%) were above 35 years of age. The mean age of the mothers of newborns in this study was $26.1 \pm 5.9$ years.

Newborn age on admission was $<24 \mathrm{H}$ in $69.5 \%$ of the cases and $\geq 24 \mathrm{H}$ in $30.5 \%$ of the cases. The mean age of newborns on admission was $2 \pm 5$ days. The sex ratio was 1:1.

\section{- Clinical characteristics}

During pregnancy, 49 (24.1\%) of the mothers of the newborns had signs of infection such as malaria in 21 cases (10.3\%) and genito-urinary infections in 28 cases (13.8\%).

The length of the pregnancy was lower than 37 WA in 70 cases (34.5\%) and higher than 37 WA in 133 cases (65.5\%). Mean gestational age was $37.3 \pm 3.6$ WA.

Vaginal delivery was the most common mode of delivery (64.5\% in comparison to $35.5 \%$ for caesarean deliveries).

Depending on the place of birth, 131 newborns were delivered at the CHUD-Borgou's maternity department (in born) (64.5\%), and 72 were delivered outside of the same maternity department (out born) (35.5\%).

The main reasons for admission were, in descending order, preterm delivery at $25.1 \%$ (51/203), respiratory distress at $15.8 \%(32 / 203)$ and infectious anamnesis at $14.3 \%(29 / 203)$.

Figure 1 shows the distribution of newborns based on physical symptoms present on admission.

\section{- Paraclinical characteristics}

\section{- Blood culture}

Out of the 203 newborns suspected of bacterial infection, samples were collected once from 95 newborns for a blood culture. Out of the 95 blood cultures performed, 14 (14.7\%) were positive. Table 1 lists the types of bacteria that were isolated.

\section{- Cytobacteriological analysis of gastric fluid}

Of all the newborns transferred from the CHUD-Borgou maternity department, 60 were subject to gastric fluid collection, including 13 (21.7\%) who tested positive for bacteria. Among the latter, there were 3 positive cases with 2 types of bacteria at the same time. The bacteria that were identified are listed in Table 2 based on their frequency.

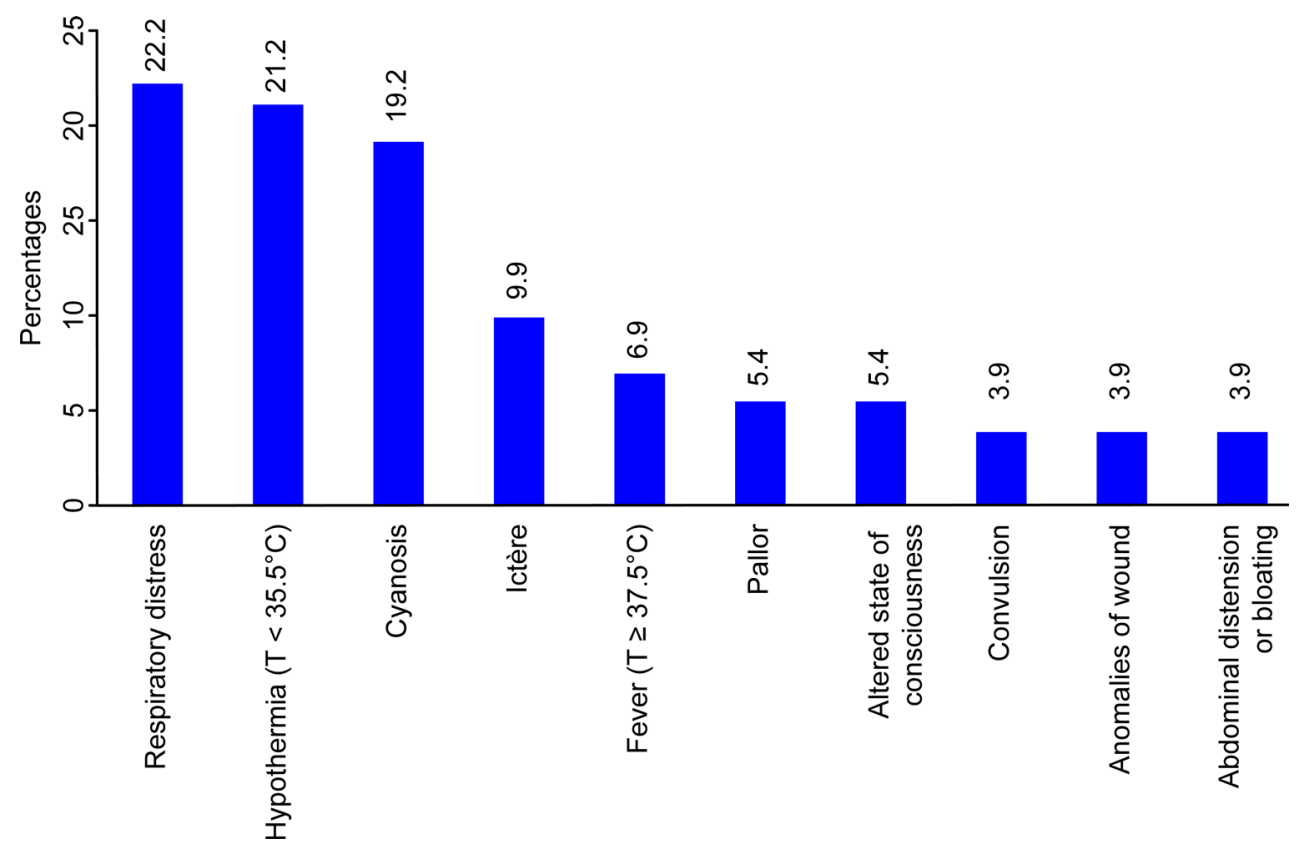

Figure 1. Distribution of newborns hospitalized in the neonatology unit of CHUD-Borgou from June 1 to August 31, 2013 according to physical symptoms shown on admission. 
Table 1. Frequency of bacteria isolated in blood culture among newborns hospitalized in neonatology unit of CHUD-Borgou from June 1 to August 31, 2013.

\begin{tabular}{ccc}
\hline & Numbers & \% \\
\hline Escherichia coli & 5 & 35.8 \\
Staphylococcus aureus & 3 & 21.5 \\
Klebsiella pneumoniae & 2 & 14.3 \\
Pseudomonas aeruginosa & 1 & 7.1 \\
Staphylococcus epidermidis & 1 & 7.1 \\
Staphylococcus saprophyticus & 1 & 7.1 \\
Streptococcus agalactiae & 1 & 7.1 \\
Total & $\mathbf{1 4}$ & $\mathbf{1 0 0 . 0}$ \\
\hline
\end{tabular}

Table 2. Frequency of germs isolated during cytobacteriological analysis of gastric fluid in neonates hospitalized in CHUD-Borgou's neonatology unit from June 1 to August 31, 2013.

\begin{tabular}{ccc}
\hline & Numbers & $\%$ \\
\hline Escherichia coli & 9 & 69.2 \\
Klebsiella pneumoniae & 3 & 23.1 \\
Staphylococcus aureus & 3 & 23.1 \\
Staph saprophyticus & 1 & 7.7 \\
\hline
\end{tabular}

Table 3. Levels of sensitivity to antibiotics tested in vitro for the different bacteria found during blood culture and in gastric fluid samples.

\begin{tabular}{|c|c|c|c|c|c|c|c|c|c|c|c|c|c|c|c|}
\hline & PEN & AMP & AMX & AMC & CXM & CTX & CRO & CAZ & IPM & HLG & NET & CIP & OFX & VAN & FOS \\
\hline Staphylococcus aureus $(\mathrm{n}=6)$ & 0 & 0 & 0 & 66.7 & 16.7 & 0 & 16.7 & 16.7 & 83.3 & 83.3 & 100 & 66.7 & 66.7 & 50 & 66.7 \\
\hline Staphylococcus saprophyticus $(n=2)$ & 0 & 0 & 0 & 50 & 0 & 0 & 0 & 0 & 50 & 100 & 100 & 50 & 50 & 50 & 50 \\
\hline Staphylococcus epidermidis $(\mathrm{n}=2)$ & 100 & 100 & 100 & 0 & 0 & 100 & 0 & 100 & 100 & 100 & 100 & 100 & 100 & 100 & 100 \\
\hline Streptococcus agalactiae $(\mathrm{n}=1)$ & 0 & 0 & 100 & 100 & 100 & 100 & 100 & 100 & 100 & 0 & 0 & 0 & 0 & 0 & 0 \\
\hline Escherichia coli $(\mathrm{n}=14)$ & 0 & 21.4 & 14.3 & 0 & 35.7 & 35.7 & 35.7 & 64.3 & 64.3 & 71.4 & 57.1 & 35.7 & 71.4 & 0 & 21.4 \\
\hline Pseudomonas aeruginosa $(\mathrm{n}=5)$ & 0 & 0 & 0 & 0 & 0 & 100 & 100 & 0 & 100 & 100 & 0 & 100 & 100 & 0 & 0 \\
\hline Klebsiella pneumoniae $(\mathrm{n}=1)$ & 0 & 0 & 20 & 20 & 0 & 20 & 20 & 40 & 60 & 80 & 60 & 40 & 40 & 0 & 0 \\
\hline
\end{tabular}

PEN = PENICILLIN; AMP = AMPICILLIN; AMX = AMOXICILLIN; AMC = AMOXICILLIN + CLAVULANIC ACID; CXM = CEFUROXIME; CTX = CEFOTAXIME; CRO = CEFTRIAXONE; CAZ = CEFTAZIDIME; IPM = IMIPENEM; HLG = GENTAMICIN; NET = NETILMICIN; CIP = CIPROFLOXACIN; OFX = OFLOXACIN; VAN = VANCOMYCIN; FOS = FOSFOMYCIN .

\section{- Results of antimicrobial susceptibility testing}

Table 3 displays the results of the antimicrobial susceptibility testing performed on the pathogens found during blood culture and in the gastric fluid.

\section{- Lumbar puncture}

Among the 203 newborns who were suspected of neonatal bacterial infection, 85 were suspected of bacterial meningitis and had a lumbar puncture with 14 cases (16.5\%) of pleocytosis.

In all the CSF samples, no pathogen was identified during either the Gram direct test or the culture.

\section{- Other preclinical tests}

Of the 203 newborns who were suspected of neonatal bacterial infection, 168 CRP tests were performed, and 55 of these were positive for bacterial infection, i.e., $32.7 \%$. The white blood cell count was pathological in $22.1 \%$ of the cases.

\section{- Locations of neonatal bacterial infection}

Figure 2 shows the distribution of infected newborns according to the location of the neonatal bacterial infection. 


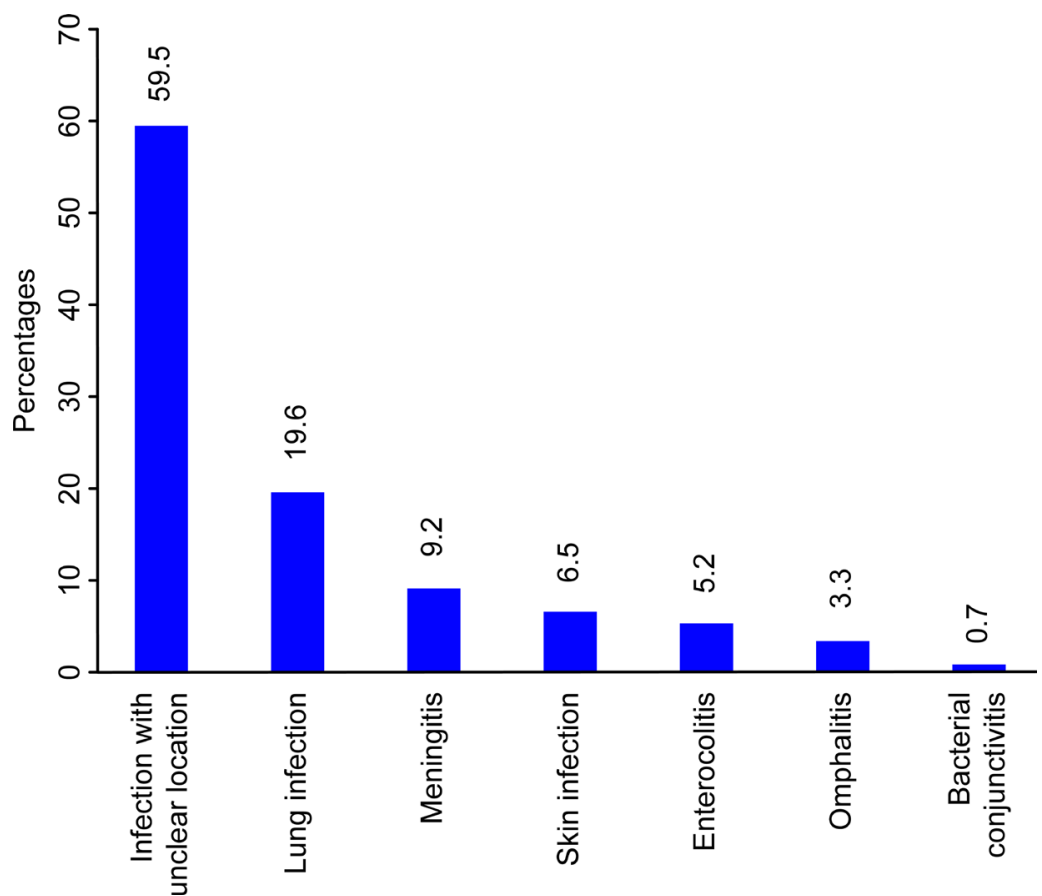

Figure 2. Distribution of infected newborns hospitalized in the neonatology unit of CHUDBorgou from June 1 to August 31, 2013 according to infection location ( $\mathrm{N}=153)$.

Table 4. Factors associated with neonatal bacterial infection (NNBI) among newborns hospitalized in the CHUD-Borgou neonatal care unit from June 1 to August 31, 2013.

\begin{tabular}{|c|c|c|c|c|c|}
\hline & \multicolumn{3}{|c|}{ NNBI } & \multirow{2}{*}{$\mathbf{R R}$} & \multirow{2}{*}{$\begin{array}{c}\text { and } \mathrm{CI}(\mathrm{RR}) \\
95 \%\end{array}$} \\
\hline & Yes & No & Total & & \\
\hline Place of birth & & & & & $p=0.000$ \\
\hline In born & 88 & 43 & 131 & & 1 \\
\hline Out born & 65 & 7 & 72 & 1.34 & {$[1.17 ; 1.55]$} \\
\hline Newborns' age & & & & & $p=0.003$ \\
\hline$<24 \mathrm{H}$ & 98 & 43 & 141 & & 1 \\
\hline$\geq 24 \mathrm{H}$ & 55 & 7 & 62 & 1.28 & {$[1.11 ; 1.47]$} \\
\hline \multicolumn{2}{|c|}{ Infection disease during pregnancy } & & & & $\mathrm{p}=\mathbf{0 . 0 2}$ \\
\hline Yes & 44 & 5 & 49 & 1.27 & {$[1.10 ; 1.46]$} \\
\hline No & 109 & 45 & 154 & & 1 \\
\hline
\end{tabular}

\section{- Progression under treatment of clinical state of infected newborns}

Favorable evolution under treatment was noted in $45.7 \%$ of the cases. In $32.7 \%$ of the cases, discharge against medical advice occurred. Lethality associated with bacterial infection was estimated to be $21.6 \%$.

\section{- Factors associated with neonatal bacterial infection}

Table 4 shows the factors that were associated with neonatal bacterial infection by specifying each modality, the relative risk (RR) and the confidence interval (CI).

\section{Discussion}

At the end of the study, neonatal bacterial infections accounted for $63.75 \%$ of admissions in the CHUD-Borgou neonatal care unit. This proportion is significant, but it nevertheless shows that not all newborns who are admitted in the neonatal care unit are infected. In addition, it questions if systematically placing newborns on a regime of antibiotics, even those who do not show signs of bacterial infection, should be standard protocol. The fre- 
quency of neonatal bacterial infections is near 65.2\%, as reported by Yao Atteby et al. in 2006 during a prospective study performed over the course of 5 months in the neonatal care unit of Treichville University Teaching Hospital (Ivory-Coast). [3] However, it is lower than 73.9\%, which was obtained by Koueta et al. in 2007 in Burkina Faso [9]. The differences noted between the frequencies of neonatal bacterial infections in those Sub-Saharan African countries may be a result of the different methodological approaches used and the criteria governing neonatal bacterial infection diagnosis.

Among all newborns, 95 benefitted from a blood culture with 14.7\% positivity. Low positivity in apparently infected newborns is due to an anti-biotherapy practice in our maternity departments where the woman attending the delivery is systematically put on ampicillin by intravenous administration without a vaginal swab to perform testing for Group B streptococcus in the event of preterm or prolonged rupture of the membranes. In addition, low positivity may also occur because in all cases, there is only one sample collected from the newborn on admission, whereas it is established that multiple blood samples are required to increase the possibility of blood culture positivity when the fever reaches a climax or in the event of hypothermia. This frequency is similar to the ones reported by Chabi et al. and by Balaka et al. who found frequencies of $13.8 \%$ and $11.6 \%$, respectively [10] [11]. Moreover, it is lower than the ones reported by Mhada et al., Yao Atteby et al., Andrianarivelo et al. and Ayivi et al. who found 22.4\%, 35.7\%, 52.4\% and 58.3\% positive blood cultures, respectively [3] [12]-[14]. The difference noted between our results and those in the literature would be related to the repetition of blood collection for blood cultures in the same child and also to the sample size and duration of the study. The other reason that may explain the low positivity of the blood cultures is self-medication and, particularly, almost systematic antibiotic prescriptions for newborns at birth in our hospital.

Regarding the bacteria identified during the blood cultures, the most common were Gram-negative bacilli (Escherichia coli in $35.8 \%$ of the cases and Klebsiella pneumoniae in $14.3 \%$ of the cases) and Gram-positive cocci, especially Staphylococcus aureus, in $21.5 \%$ of the cases. These results are consistent with those obtained by several researchers in Sub-Saharan Africa. In fact, Mhada et al. reported that Staphylococcus aureus was the cause of neonatal bacterial infections in $36.5 \%$ of cases and that Klebsiella pneumoniae and Escherichia coli were responsible in $29.7 \%$ and $18.9 \%$ of the cases, respectively [12]. Klebsiella pneumoniae was more common (51.6\%) in the study of Yao Atteby et al. followed by Escherichia coli (16.1\%) and Staphylococcus aureus (9.7\%) [3]. For Ayivi et al., Klebsiella pneumoniae was predominant with a frequency of 36\%, followed by Escherichia coli (20\%) and Proteus mirabilis (8\%) [13]. In 2001 in Nigeria, Adejuyigbe et al. reported the predominance of Staphylococcus aureus and Pseudomonas aeruginosa [15]. The presence of Pseudomonas aeruginosa, a hospital-based pathogens, in our study is due to newborn infection during care in the maternity department before admission into the neonatal care unit.

In general, isolated bacteria during blood cultures exhibited a low level of sensitivity to commonly used antibiotics. Several pathogens were already resistant to antibiotics such as fosfomycin, vancomycin and imipenem, which did not receive marketing authorization (MA) in Benin in 2013. This situation must be of great concern for all health workers and the whole population of Benin in general with regard to the use of antibiotics. This research work highlights an overall resistance of isolated bacteria to blood culture as well as to cytobacteriological analysis of gastric fluid, to amino-penicillins and penicillin G according to the findings obtained by Ayivi et al., Mhada et al. and Andrianarivelo et al. [12]-[14]. However, unlike Mhada et al. and Cisse et al., who reported a low sensitivity with regard to gentamicin and netilmicin [12] [16], in our series, germs presented a better or worse sensitivity to aminoglycosides except Streptococcus agalactiae, which was resistant to gentamicin and netilmicin. This high resistance to amino-penicillins could be because of the inappropriate and excessive use of those molecules throughout the country. In fact, self-medication fueled by the selling of any type of drugs, including antibiotics, on market store shelves and uncontrolled prescriptions by health professionals has led to a situation of great concern. National health authorities must fight systematic prescriptions of amoxicillin for newborns after delivery in maternity departments. The three main pathogens found in the study were sensitive to imipenem, a molecule of last resort that is not frequently used because it is unknown to most health workers. Moreover, it is very expensive and is thus out of reach for the population.

Regarding the location of the infection, no precise source of infection was found in six cases out of ten. The main locations that were identified were pulmonary (19.6\%), meningeal (9.2\%) and cutaneous (6.5\%). Our results are similar to those of other authors such as Dan et al., Yao Atteby et al., Akaffou et al. and Ayivi et al. who identified a large majority of infections with unclear locations in $70.6 \%, 65.6 \%, 61.5 \%$ and $48 \%$ of the cases, respectively [2] [3] [13] [17]. Those similarities show that infections were most often septicemic in the 
newborn. Regarding factors that are associated with neonatal bacterial infections, this research work demonstrated that "out born" newborns had 1.34 times higher risk of infection than "in born" newborns $(p=0.000)$. In addition, an age under 24 hours of life multiplied the infection risk by $1.28(\mathrm{p}=0.003)$. The presence of an infectious pathology during pregnancy also influenced the occurrence of infection; in this case, the risk of neonatal bacterial infection was multiplied by $1.27(\mathrm{p}=0.02)$. Other factors associated with neonatal bacterial infection that are reported in literature, such as a premature rupture of membranes before 12 hours, abnormalities of the amniotic fluid, poor APGAR score, low birth-weight, maternal fever and quality of antennal care (ANC), were not identified in this study [3] [10] [17].

\section{Conclusion}

The following conclusions have emerged from this research work. More than two out of three newborns who were hospitalized in the CUHD-Borgou neonatal care unit had a neonatal bacterial infection. In 6 cases out of 10, the infection location was not clear. Biologically, less than 2 blood culture samples out of 10 were positive. The main bacterial germs identified were Escherichia coli, Klebsiella pneumoniae and Staphylococcus aureus, which were sensitive to aminoglycosides. Progression was characterized by death in one case out of five. The factors associated with infection occurrence were the age of newborns on admission, the presence of infectious disease during pregnancy and the place of birth. This study notes the adverse effect of the nearly systematic and excessive use of antibiotics in newborns. Considering the limitations noted, a study covering a longer period of time that was provided with appropriate material resources would help to assess the importance and the causes of neonatal bacterial infections in the unit.

\section{Financial Assistance}

Hospital subsidization.

\section{Conflict of Interest}

None.

\section{References}

[1] Lawn, J. and Kerber, K. (2006) Opportunities for Africa’s Newborns: Practical Data, Policy and Programmatic Support for Newborn Care in Africa. PMNCH, Cape Town.

[2] Dan, V., Alihonou, E., Hazoumè, F., Ayivi, B., Koumakpaï, S., Atchadé, D., et al. (1991) Management of Sick Newborn in Tropical Areas: Experience of the Neonatal Care Unit of Cotonou. Médecine d'Afrique Noire, 38, 842-849.

[3] Yao Atteby, J., Cissé, L., Orega, M., Attimere, Y., Oulaï, S., Djadan, M., et al. (2006) Neonatal Infections in Abidjan Clinical and Etiological Aspects. Médecine d'Afrique Noire, 53, 124-126.

[4] Azoumah, K., Balaka, B., Aboubakari, A., Matey, K., Yolou, A. and Agbéré, A. (2010) Neonatal Morbidity and Mortality in the University Teaching Hospital of Kara (Togo). Médecine d'Afrique Noire, 57, 109-112.

[5] ANAES (Agence Nationale d'Accreditation et d'Evaluation en Sante) (2003) Diagnosis and Treatment of Early Bacterial Infection in Newborns. Archives de Pédiatrie, 10, 489-496.

[6] Blond, M., Poulain, P., Gold, F., Bingen, E., Watier, H. and Quentin, R. (2005) Maternal and Fetal Bacterial Infection. EMC-Obstetric Gynecology, 2, 28-90.

[7] Ayivi, B., Quenum, A., Traoré, E. and Zonon, A. (2004) Benin Experience on Integrated Management of Childhood Illness Algorithm in the Newborn. In: Book of Abstracts of the Information and Brainstorming Day on Newborn Care Organized by the Benin Society of Pediatrics (SOBEPED), Mars, Cotonou, Benin.

[8] Lahbabi, M.S., Benomar, S., Bouskraoui, M., Adnana, F., Sqalli, M. and Benbachir, M. (1997) Neonatal Purulent Meningitis. Analytical Study of 94 Observations in Casablanca. Médecine et Maladies Infectieuses, 27, 88-92. http://dx.doi.org/10.1016/S0399-077X(97)80077-7

[9] Kouéta, F., Yé, D., Dao, L., Néboua, D. and Sawadogo, A. (2007) Neonatal Morbidity and Mortality from 2002 to 2006 in the Charles de Gaulle Pediatric University Teaching Hospital of Ouagadougou (Burkina Faso). Santé, 4, 187-191.

[10] Chiabi, A., Djoupomb, M., Mah, E., Nguefack, S., Mbuagbaw, L., Zafack, J., et al. (2011) The Clinical and Bacteriogical Spectrum of Neonatal Sepsis in a Tertiary Hospital in Yaounde, Cameroon. Iranian Journal of Pediatrics, 21, 
441-448.

[11] Balaka, B., Bonkoungou, B., Matey, K., Napo-Bitantem, S., Kessie, K. and Assimadi, K. (2004) Neonatal Sepsis: Bacteriological and Evolutionary Aspects in the University Teaching Hospital of Lomé, Togo. Bulletin de la Société de Pathologie Exotique, 97, 97-99.

[12] Mhada, T.V., Fredrick, F., Matee, M.I. and Massawe, A. (2012) Neonatal Sepsis at Muhimbili National Hospital, Dar es Salaam, Tanzania; Aetiology, Antimicrobial Sensitivity Pattern and Clinical Outcome. BMC Public Health, $12,904$. http://dx.doi.org/10.1186/1471-2458-12-904

[13] Ayivi, B., Massougbodji, A., Aïssi, E., Alihonou, E., Hazoumè, F. and Dan, V. (1989) Neonatal Infections in the National University Teaching Hospital of Cotonou: Epidemiological, Clinical, Bacteriological and Therapeutic Approaches. Médecine d'Afrique Noire, 36, 300-311.

[14] Andrianarivelo, A., Rafaravavy, N., Rafalimanana, C., Andriantahiana, T. and Robinson, A. (2010) Bacteriological Profile of Neonatal Infections at the Neonatal Intensive Care Unit of the Maternity of Befelatanana. Revue d'Anesthésie Réanimation et Médecine d'Urgence, 2, 1-4.

[15] Adejuyigbe, E.A., Adeodu, O.O., Ako-Nai, K.A., Taiwo, O. and Owa, J.A. (2001) Septicaemia in High Risk Neonates at a Teaching Hospital in Ile-Ife, Nigeria. East African Medical Journal, 78, 540-543. http://dx.doi.org/10.4314/eamj.v78i10.8965

[16] Cissé, C., Mbengue-Diop, R., Moubarek, M., Ndiaye, O., Dotou, C., Boye, C., et al. (2001) Neonatal Bacterial Infections in the University Teaching Hospital of Dakar. Obstetric Gynecology and Fertility, 29, 433-439.

[17] Akaffou, E., Amon-Tanoh, F., Lasme, E., Ehua-Amangoua, E. and Kangah, D. (1998) Neonatal Bacterial Infections in Hospital Ward in Abidjan. Médecine d'Afrique Noire, 45, 414-417.

\section{Abbreviations and Acronyms}

1) CHUD-Borgou: Centre Hospitalier Universitaire Départemental du Borgou = Borgou Regional University Teaching Hospital

2) WHO: World Health Organization

3) UNICEF: United Nations Children's Fund

4) USAID: United States Agency for International Development

5) UNFPA: United Nations Population Fund 